\title{
Synthesis of Polyazomethinesters and Relationship between Their Structures and Thermal Stability
}

\author{
Danuta SEูK \\ Institute of Polymer Chemistry, Polish Academy of Sciences, \\ P. O. Box 49, 41-800 Zabrze, Poland.
}

(Received June 6, 1981)

\begin{abstract}
A series of aromatic polyesters containing azomethine groups in the main chain
\end{abstract} having a general formula:<smiles>CC(C)(C)Oc1ccc(C=N[B]N=Cc2ccc(OC(=O)[In]C(=O)C(C)(C)c3ccccc3)cc2)cc1</smiles>

was obtained. The relationship between structure and thermal stability of these polymers was studied.

KEY WORDS Aromatic Polyesters / Bisphenols / Schiff Bases / Thermal Stability /Polycondensation /

Thermal stability of polymers is known to be determined by the energy of interatomic bonds, the possibility of the formation of intermolecular bonds and resonance stabilization, all of these factors depending on polymer chain structure. The high thermal stability of aromatic polyesters as well as aromatic Schiff's polybases prompted us to study the properties of aromatic polyesters with azomethine groups in the main chain. Only a few works have been published on the synthesis of such polymers. Rovelio and Sirigu synthesized polyesters and polycarbonates with azine groups in the chain using 4,4'-dihydroxy- $\alpha, \alpha^{\prime}$-dimethylbenzalazine ${ }^{1-3}$ as the bisphenolic component.

Polyesters with azomethine groups and with flexible spacers in the main chain were reported by Blumstein et al. ${ }^{4,5}$ The synthesis of aromatic polyesters with azomethine groups was performed by the polycondensation of bisphenols (shown in Figure 1) with tere- and isophthaloyl chloride.

Except for bisphenol 5, no use of bisphenols for polyester synthesis has been reported in the literature. $^{5}$

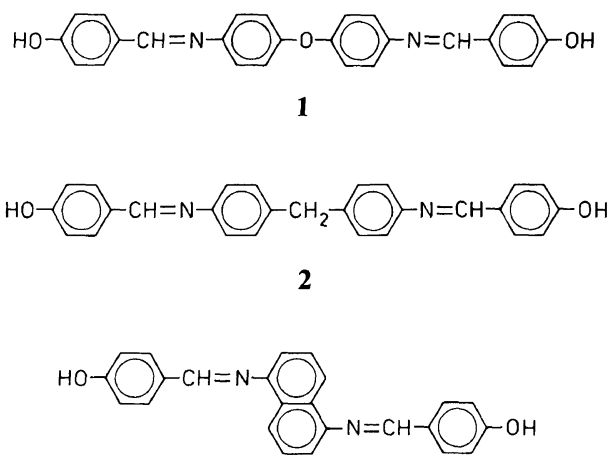

3

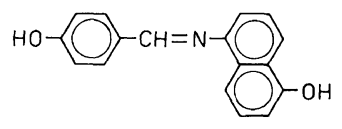

4

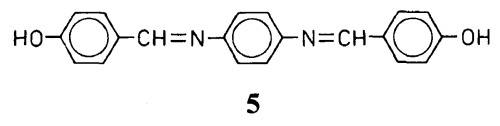

Figure 1. Structure of the bisphenols. 
D. SẹK




Polyazomethinesters, Structure and Thermal Stability

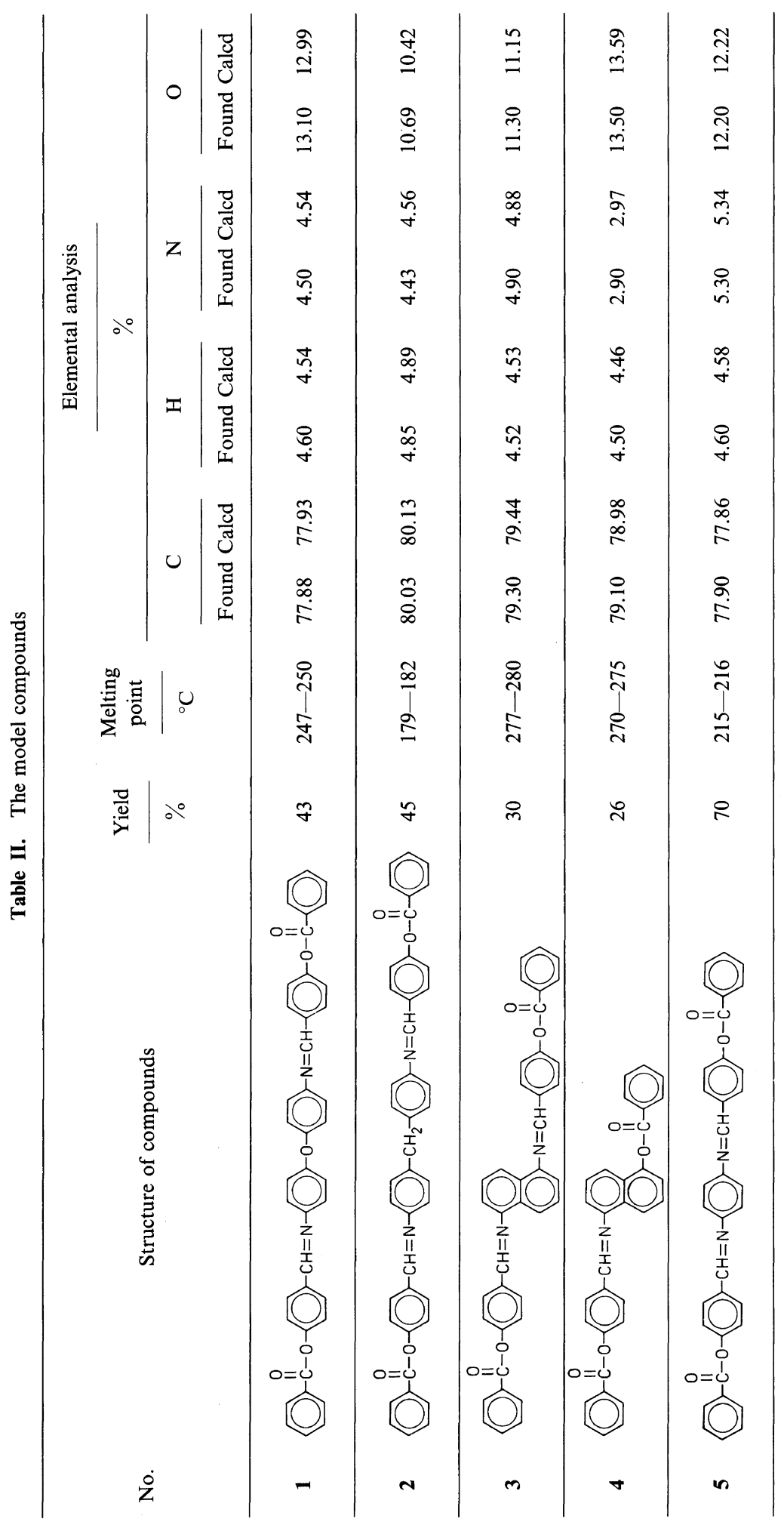




\section{EXPERIMENTAL}

\section{Synthesis of Bisphenols}

$0.2 \mathrm{~mol}$ of 4-hydroxybenzaldehyde, $0.1 \mathrm{~mol}$ of a diamine, $0.05 \mathrm{~g}$ of $p$-toluenesulphonic acid and $500 \mathrm{ml}$ of toluene were heated at the boiling temperature in a flask fitted with Dean-Stark trap until water evolved.

The crude product was then filtered, dried and recrystallized from $n$-butyl alcohol. The properties of the bisphenols used are presented in Table I.

\section{Synthesis of Model Compounds}

Into $0.0025 \mathrm{~mol}$ of a bisphenol and $0.005 \mathrm{~mol}$ of triethylamine in $20 \mathrm{ml}$ of methylene chloride, 0.005 mol of benzoyl chloride in $20 \mathrm{ml}$ of methylene chloride was added, while the mixture was stirred at $20^{\circ} \mathrm{C}$. After $30 \mathrm{~min}$ the reaction mixture was poured into $100 \mathrm{ml}$ of ethanol, filtered and dried.

The properties of the model compounds are shown in Table II.

\section{Polycondensation}

The polycondensation of the bisphenols with tere- and isophthaloyl chloride proceeded according to the scheme presented in Figure 2, and was carried

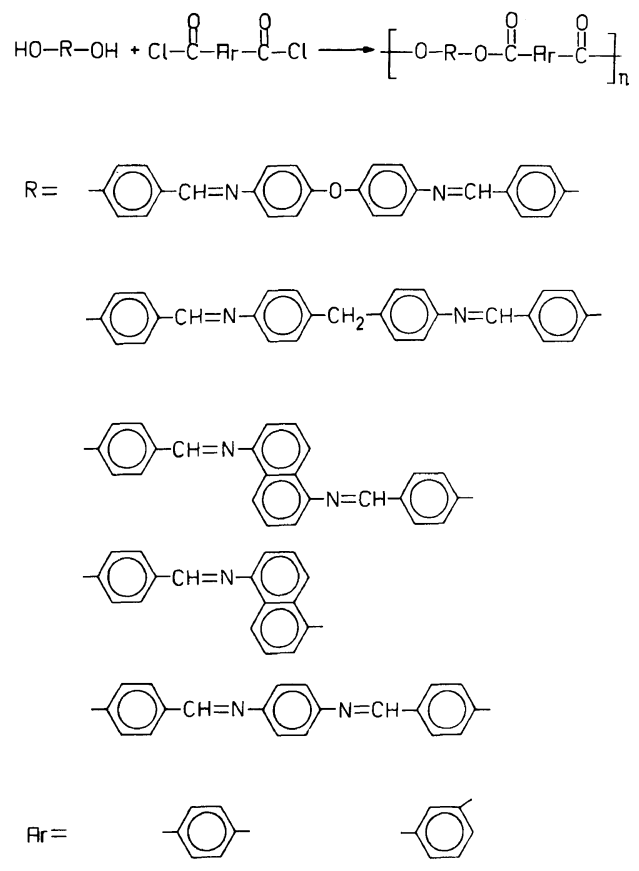

Figure 2. Scheme of the polycondensation reaction. out using the low temperature solution method as follows:

Into $0.005 \mathrm{~mol}$ of a bisphenol and $0.010 \mathrm{~mol}$ of triethylamine in $25 \mathrm{ml}$ of methylene chloride, 0.005 mol of acid chloride in $25 \mathrm{ml}$ methylene chloride was added at $20^{\circ} \mathrm{C}$. After $30 \mathrm{~min}$ of stirring the reaction mixture was poured into $100 \mathrm{ml}$ of ethanol, filtered and dried. The properties of the polymers are presented in Table IV.

\section{Measurements}

Infrared spectra were taken in nujol with a UR-20 (Zeiss apparatus).

The UV spectra were measured in methanol at a concentration of $10^{-5} \mathrm{moll}^{-1}$ on a Specord (Zeiss apparatus).

The NMR spectra were recorded on a XL-100 Varian spectrometer for samples dissolved in deuterated chloroform, using HMDSO as the internal standard.

The mass analysis was made on a LKB 9000 spectrometer; the energy of the electron beam was $70 \mathrm{eV}$ and the source temperature was $290^{\circ} \mathrm{C}$.

The thermogravimetric measurements were performed in air at 1 atm on a derivatograph ( $F$. Paulik, J. Paulik, and L. Erdley), at a heating rate of $10^{\circ} \mathrm{C} \mathrm{m^{-1 }}$ using the $P t-P t / R h$ thermocouple. Diffractograms were recorded by an X-ray diffractometer DRON-1.5 with goniometer GUR-5. NiFiltered $\mathrm{Cu} K \alpha$ radiation was used at $U=37 \mathrm{kV}$ and $I=14 \mathrm{~mA}$.

The content of the crystalline phase in the polymers was estimated on the basis of the shape of the diffractogram.

\section{RESULTS AND DISCUSSION}

The structure of the bisphenols obtained was confirmed by mass, infrared, UV and NMR spectroscopy methods. The infrared spectra show the presence of a strong band at $1620-1630 \mathrm{~cm}^{-1}$ which is characteristic of the $-\mathrm{CH}=\mathrm{N}$ - bond, and a band at $3000-3300 \mathrm{~cm}^{-1}$, due to stretching vibrations of $-\mathrm{OH}$ groups. A band at $1380 \mathrm{~cm}^{-1}$, characteristic of bending vibrations of $-\mathrm{OH}$ and stretching vibrations of $-\mathrm{C}-\mathrm{O}-$ in phenols, was also observed. Absorption bands characteristic of the phenyl structures were also visible.

In the UV spectra, four bands can be found (Figure 3). Three of these are not particularly 

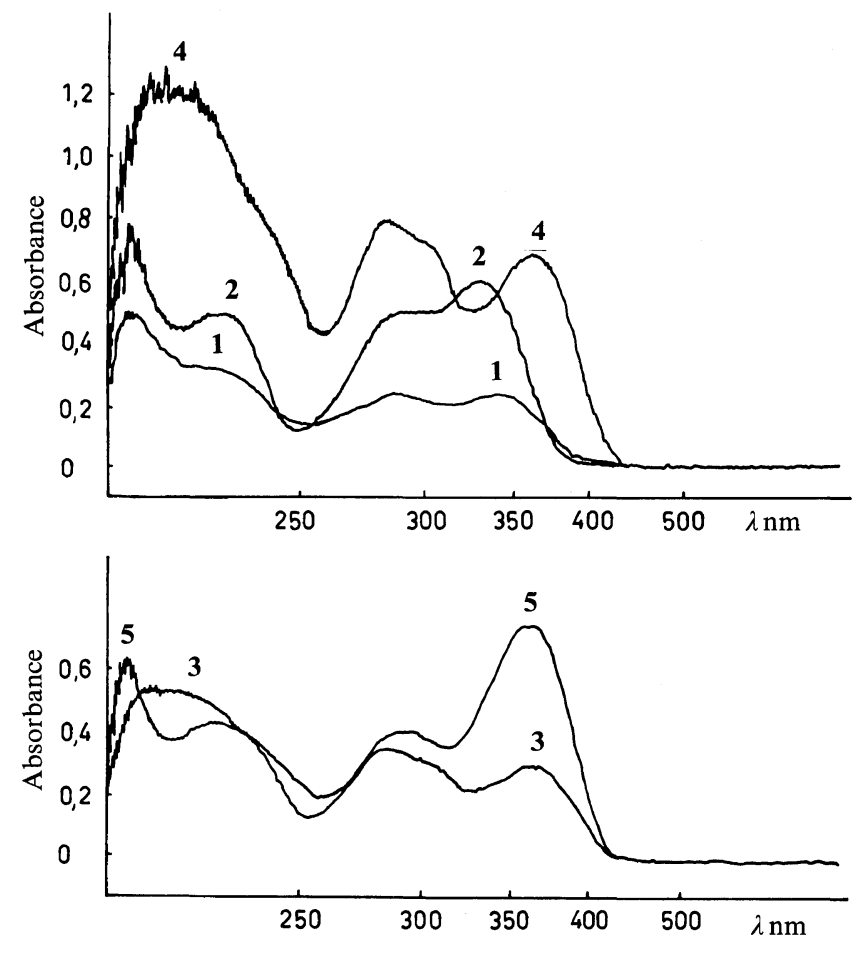

Figure 3. UV spectra of the bisphenols.

influenced by the structure of the bisphenol.

The band of the $\pi \rightarrow \pi^{*}$ transition at $330-360 \mathrm{~nm}$ is more sensitive to structural effects, and the bisphenols without bridges between the rings $\left(-\mathrm{CH}_{2}-\right.$, -O-) exhibited a greater bathochromic shift in that band.

In the NMR spectra, a singlet characteristic of hydrogen in the azomethine group and a multiplet derived from hydrogen atoms in the aromatic rings could be observed. It is interesting that in the bisphenols without bridges, all absorption bands are shifted to higher values of $\delta$ in comparison with those having - $\mathrm{O}-$ or $-\mathrm{CH}_{2}-$ bridges in the molecule.

This was also confirmed by electronic spectra where bands responsible for the $\pi \rightarrow \pi^{*}$ transition for those compounds shifted to the longer wavelength region.

The results of elemental and spectroscopic analyses confirmed the structure of the model compounds (Table II). In the infrared spectra, absorption bands at $1630 \mathrm{~cm}^{-1}$ (characteristic of $-\mathrm{CH}=$ $\mathrm{N}-$ groups) and at $1750 \mathrm{~cm}^{-1}$ (characteristic of carbonyl groups in the esters) are present along with absorption bands due to aromatic rings.

The melting points of the model compounds were determined using a hot plate with a polarising microscope at a heating rate of $4^{\circ} \mathrm{C} \min ^{-1}$.

A transition to an anisotropic liquid phase was observed during the melting of compounds 3,4 , and 5 (in Table II), and then, with further heating there occurred a transition to an isotropic liquid.

These phenomena were observed at the second and following heating runs (Table III). More detailed investigations concerning these phenomena using the model compounds and polyesters will be carried out in the future. Infrared spectra of polyesters are very similar to those of model compounds and show in addition weak absorption bands in the region of $3200-3400 \mathrm{~cm}^{-1}$, characteristic of $-\mathrm{OH}$ vibrations.

The terephthalic and isophthalic polyesters obtained (Table IV) did not melt until their decomposition temperature had been reached.

The thermogravimetric analysis performed in air 
D. SĘK

Table III. Phase transition temperatures ${ }^{a}$ of the model compounds

\begin{tabular}{|c|c|c|c|}
\hline \multirow{2}{*}{$\frac{\text { Compound }}{\text { No. as in Table II }}$} & \multirow{2}{*}{$\begin{array}{l}\text { Heating run } \\
4^{\circ} \mathrm{C} \mathrm{min}^{-1}\end{array}$} & \multicolumn{2}{|c|}{ Phase transition temperature ${ }^{b}$} \\
\hline & & \multicolumn{2}{|c|}{${ }^{\circ} \mathrm{C}$} \\
\hline & & $\mathrm{Ta}$ & $\mathrm{Ti}$ \\
\hline \multirow{2}{*}{3} & I & $277-280$ & $300-330$ \\
\hline & II & 270 & $290-330$ \\
\hline \multirow{2}{*}{4} & I & $270-275$ & $320-325$ \\
\hline & II & \multicolumn{2}{|c|}{ No phase transition observed } \\
\hline \multirow{2}{*}{5} & I & 215 & $300-330$ \\
\hline & II & 215 & $300-330$ \\
\hline
\end{tabular}

a Determined by an optical methods.

b Ta, transition from the solid to the anisotropic liquid phase.

$\mathrm{Ti}$, transition from the anisotropic to the isotropic liquid phase.

$\operatorname{Red}^{a}$

Table IV. Properties of the polyesters

\begin{tabular}{|c|c|c|c|c|c|c|c|}
\hline \multirow{2}{*}{$\begin{array}{l}\text { Polyesters from } \\
\text { bisphenols }\end{array}$} & \multirow[b]{2}{*}{ Yield } & \multirow[b]{2}{*}{$\eta_{\text {red }}{ }^{\mathrm{a}}$} & \multicolumn{5}{|c|}{ Thermogravimetric analysis in air } \\
\hline & & & \multirow{2}{*}{$\begin{array}{l}\text { Temp of start } \\
\text { of decomp. }\end{array}$} & \multirow{2}{*}{$\begin{array}{l}\text { Temp of max } \\
\text { of decomp. }\end{array}$} & \multirow{2}{*}{$\begin{array}{l}\text { Temp of end } \\
\text { of decomp. }\end{array}$} & \multirow{2}{*}{$\begin{array}{c}\text { Temp of } 25 \% \\
\text { weight loss }\end{array}$} & \multirow{2}{*}{$\begin{array}{l}\text { Residue at } \\
900^{\circ} \mathrm{C}\end{array}$} \\
\hline & $\%$ & $\mathrm{dlg}^{-1}$ & & & & & \\
\hline & & & ${ }^{\circ} \mathrm{C}$ & ${ }^{\circ} \mathrm{C}$ & ${ }^{\circ} \mathrm{C}$ & ${ }^{\circ} \mathrm{C}$ & $\%$ \\
\hline \multicolumn{8}{|l|}{ Terephthalic: } \\
\hline 1 & 74 & 0.07 & 320 & 400,590 & 680 & 450 & 8.5 \\
\hline 2 & 74 & 0.14 & 340 & 570 & 690 & 470 & 5.0 \\
\hline 3 & 80 & 0.05 & 380 & 430,640 & 750 & 480 & 13.0 \\
\hline 4 & 85 & 0.11 & 380 & 580 & 710 & 500 & 12.0 \\
\hline 5 & 88 & 0.08 & 340 & 450,570 & 680 & 460 & 11.0 \\
\hline \multicolumn{8}{|l|}{ Isophthalic: } \\
\hline 1 & 88 & 0.04 & 315 & 370,600 & 800 & 440 & 4.0 \\
\hline 2 & 97 & $0.12^{\mathrm{b}}$ & 325 & 330,580 & 760 & 480 & 6.5 \\
\hline 3 & 98 & $0.08^{b}$ & 370 & 380,620 & 800 & 480 & 6.5 \\
\hline 4 & 96 & $0.08^{\mathrm{b}}$ & 360 & 380,600 & 850 & 500 & 8.0 \\
\hline 5 & 89 & 0.04 & 330 & 390,580 & 670 & 450 & 5.0 \\
\hline
\end{tabular}

a Determined at concn. of $1 \mathrm{~g} / 100 \mathrm{ml}$ of conc. $\mathrm{H}_{2} \mathrm{SO}_{4}$.

b Determined at concn. of $1 \mathrm{~g} / 100 \mathrm{ml}$ of $o$-chlorophenol, $20^{\circ} \mathrm{C}$.

indicated that the terephthalic polyesters had high thermal stability while temperatures marking the beginning of decomposition depended on the structure of the bisphenol used. Polyesters with naphthyl rings in the molecules are more thermally stable than those with phenyl rings. Bridges $\left(-\mathrm{CH}_{2}-,-\mathrm{O}-\right)$ decrease the thermal stability. The same effect was observed in the isophthalic polyesters (Table IV) while isophthalic polyesters were generally less thermally stable than terephthalic ones.

The polyesters obtained from terephthaloyl chloride and bisphenols with azomethine groups were soluble only in conc. $\mathrm{H}_{2} \mathrm{SO}_{4}$, hot $m$-cresol and $o$ chlorophenol. Generally, isophthalic polyesters are more soluble than terephthalic polyesters because of the disturbed symmetry of the polymer chain due to 
the acidic component.

The introduction of $-\mathrm{O}-$, and $-\mathrm{CH}_{2}-$ bridges into the polymer chain also improves its solubility.

The solution viscosities (Table IV) suggest rather low molecular weights of the polyesters. This is probably due to the insolubility of the polymers in the reaction mixture and their rapid precipitation.

Results of X-ray measurements showed that the terephthalic polyesters from bisphenols $\mathbf{1}, \mathbf{3}$, and 5 were about $60 \%$ in the crystalline phase, while this value for the terephthalic polyesters from bisphenols 2 and 4 was about $30 \%$.

The isophthalic polyesters from bisphenols 1 and 5 were about $50 \%$ in the crystalline phase and the other bisphenols $(2,3,4)$, about $20-30 \%$ in the crystalline phase.

The influence of crystallinity on the properties of polyesters along with the kind of influence exerted by different polycondensation methods will be published in a subsequent paper.

\section{CONCLUSIONS}

The thermal stability of polyesters with azomethine groups was found to depend on the struc- ture of the polymer chain. The terephthalic polyesters exhibited thermal stability higher than isophthalic polyesters having the same bisphenolic components.

Polyesters with naphthyl structures in the polymer chain are more thermally stable than those with phenyl structure or $\left(-\mathrm{O}-,-\mathrm{CH}_{2}-\right)$ bridges.

On the other hand, the introduction of structural units which increase thermal stability was found to lower the solubility of the polymers under consideration.

\section{REFERENCES}

1. A. Rovelio and A. Sirigu, J. Polym. Sci., Polym. Lett. Ed., 13, 455 (1975).

2. A. Rovelio and A. Sirigu, Eur. Polym. J., 15, 423 (1979).

3. A. Rovelio and A. Sirigu, Makromol. Chem., 181, 1799 (1980).

4. S. B. Clough, A. Blumstein, and E. C. Hsu, Macromolecules, 9, 123 (1976).

5. A. Blumstein, S. N. Sivaramakrishnan, Won-HoSohn, R. B. Blumstein, and S. B. Clough, Polym. Prepr., Am. Chem. Soc., Div. Polym. Chem., 20, 638 (1979). 